\title{
Efficacy and safety of combination of nifuratel tablets with Baofukang suppository on treatment and recurrence of vaginitis in pregnancy
}

\author{
Ruifang Wang, Chunxia Zhang* \\ Department of Pharmacy, Jinan Maternity and Child Care Hospital Affiliated to Shandong First Medical University, Jinan city, \\ Shandong Province, China
}

*For correspondence: Email: haonljsyq215620@163.com

Sent for review: 19 March 2020

Revised accepted: 23 May 2021

\begin{abstract}
Purpose: To investigate the effect and safety of a combination of Nifuratel tablets and Baofukang suppository in the treatment and recurrence of vaginitis in pregnant patients.

Methods: A retrospective analysis was carried out on 100 in-patients admitted between February 2019 and April 2020. They were randomly assigned to control and study groups, with 50 in each group. The control group received Baofukang suppository treatment, whilst the study group was treated with Nifuratel tablets in addition to Baofukang suppository. The two groups were compared with regard to treatment effectiveness, incidence of adverse reactions, recurrence at 1, 2 and 3 months posttreatment; time taken for disappearance of clinical symptoms, and levels of inflammatory factors 1 week after treatment. Moreover, Mental Status Scale in Non-Psychiatric Settings (MSSNS) score, and Quality of Life Index (QLI) score were compared between the groups.

Results: The study group out-performed the control group with respect to treatment effectiveness and $Q L I$ score $(p<0.05)$. Patients in the study group had significantly lower incidence of adverse reactions, degree of recurrence at 1, 2 and 3 months post-treatment, time taken for disappearance of clinical symptoms, expression levels of inflammatory factors, and MSSNS score, when compared to those in control group $(p<0.05)$.

Conclusion: Combined use of Nifuratel tablets and Baofukang suppository in the treatment of pregnant patients with vaginitis leads to significant treatment efficacy and safety, and reduced recurrence and expression levels of inflammatory factors in patients.
\end{abstract}

Keywords: Nifuratel, Baofukang suppository, Vaginitis, Pregnancy, Therapeutic effect, Recurrence, Safety

\begin{abstract}
This is an Open Access article that uses a fund-ing model which does not charge readers or their institutions for access and distributed under the terms of the Creative Commons Attribution License (http://creativecommons.org/licenses/by/4.0) and the Budapest Open Access Initiative (http://www.budapestopenaccessinitiative.org/read), which permit unrestricted use, distribution, and reproduction in any medium, provided the original work is properly credited.

Tropical Journal of Pharmaceutical Research is indexed by Science Citation Index (SciSearch), Scopus, International Pharmaceutical Abstract, Chemical Abstracts, Embase, Index Copernicus, EBSCO, African Index Medicus, JournalSeek, Journal Citation Reports/Science Edition, Directory of Open Access Journals (DOAJ), African Journal Online, Bioline International, Open-J-Gate and Pharmacy Abstracts
\end{abstract}

\section{INTRODUCTION}

Vaginitis is a common complaint among pregnant women. The main clinical manifestations are vaginal pain and itching, and abnormal secretion of body fluids. Vaginitis, which may be due to fungal and bacterial infections, is classified into bacterial vaginitis, mycotic vaginitis and trichomoniasis vaginitis [1-3]. It probably occurs in pregnant women due to changes in hormonal 
secretions during pregnancy. There is need for caution in drug intake during pregnancy, so as to avoid fetal malformation and other congenital diseases. Therefore, the health of pregnant women and their fetuses should be considered comprehensively in the treatment of vaginitis [46]. In addition, some pregnant women may ignore the importance of timely treatment of vaginitis. This may affect the delivery and health of the fetus. Generally, Nifuratel is a drug widely used for treating bacterial vaginosis, trichomoniasis vaginitis and other vaginal diseases due to its desirable effect $[7,8]$. Baofukang suppository is also used for treating diseases such as pruritus and vaginitis. This study was aimed at identifying a treatment method for pregnant patients with vaginitis. Pregnant women with vaginitis were retrospectively divided into study group and conventional-treatment control group. The two groups were compared with respect to percentage treatment effectiveness, incidence of adverse reactions, recurrence at 1 month, 2 months and 3 months post-treatment; time taken for disappearance of clinical symptoms, levels of inflammatory factors 1 week after treatment, MSSNS score and QLI score.

\section{METHODS}

\section{General patient profile}

A retrospective analysis was conducted among 100 pregnant patients with vaginitis admitted to our hospital from February 2019 to April 2020. They were randomly assigned to control group and study group, with 50 patients in each group. The patients in study group were aged 21 to 33 years, while those in the control group were aged $20-33$ years. The protocol was approved by the ethics Committee of Shandong First Medical University, with the approved no. of 2018-CL-243 and the international guidelines for human studies that you followed [9]. There were no significant differences in age, gestational age and other general data between the two groups ( $p>0.05$; Table 1).

\section{Inclusion/exclusion criteria}

\section{Inclusion criteria}

Patients aged 18 years and above, with clinical manifestations of vaginitis during pregnancy, and patients without other organic diseases or history of drug allergy, drug abuse or bad habits, were included in the study.

\section{Exclusion criteria}

Pregnant women at advanced gestational age, patients with other types of gynecological diseases, and those with gestational diabetes mellitus were excluded.

The study was approved by the ethics committee of our hospital. All patients voluntarily participated in the study and submitted signed informed consent forms.

\section{Treatments}

The control group patients were treated with Baofukang suppository (Hainan Bikai Pharmaceutical Co. Ltd.; SFDA approval No.: Z46020058; specification: 1.74 g). Before administering the drug, the patients were asked to wash their vulva with warm water, and slowly insert a suppository completely into their vaginas. The dose was 1 suppository per day, continuously for 7 days.

The study group received Nifuratel tablets (Yantai Luyin Pharmaceutical Co. Ltd.; SFDA approval no.: H20065237; specification: $0.2 \mathrm{~g}$ ), in addition to Baofukang suppository at the same dose used in the control group. Nifuratel tablet was given orally at a dose of 1 tablet 3 times per day, $30 \mathrm{~min}$ after a meal. The drug was administered continuously for 7 days.

Table 1: General information on patients

\begin{tabular}{lcccc}
\hline Variable & Study group & Control group & $\mathbf{t} / \mathbf{X}^{\mathbf{2}}$ & $\boldsymbol{P}$-value \\
\hline Age (years) & $26.28 \pm 3.00$ & $26.51 \pm 3.17$ & 0.37 & 0.71 \\
Height $(\mathrm{cm})$ & $159.86 \pm 4.77$ & $160.22 \pm 4.96$ & 0.37 & 0.71 \\
Weight $(\mathrm{kg})$ & $60.27 \pm 6.39$ & $60.43 \pm 6.82$ & 0.12 & 0.90 \\
Duration (Months) & $1.33 \pm 0.25$ & $1.35 \pm 0.24$ & 0.41 & 0.68 \\
Gestational age (Weeks) & $20.64 \pm 2.55$ & $20.29 \pm 2.38$ & 0.71 & 0.48 \\
Hypertension (n) & 5 & 8 & 0.80 & 0.37 \\
Hyperlipemia (n) $\quad$ BV(n) & 6 & 5 & 0.10 & 0.75 \\
Types $\quad$ Mycotic vaginitis $(\mathrm{n})$ & 19 & 21 & 0.17 & 0.68 \\
$\quad \quad$ Trichomonas vaginitis $(\mathrm{n})$ & 11 & 16 & 0.69 & 0.41 \\
\hline
\end{tabular}




\section{Indices evaluated}

The study compared the two groups in terms of $\%$ treatment effectiveness, incidence of adverse reactions, recurrence at 1 month, 2 months and 3 months post-treatment; time taken for disappearance of clinical symptoms, expression levels of inflammatory factors 1 week after treatment, MSSNS score and QLI score. Treatment safety was judged by the incidence of adverse reactions viz: treatment was deemed effective when no adverse reactions appeared after treatment, and clinical manifestations basically disappeared; or partially effective if no adverse reactions appeared after treatment, with some reductions in clinical manifestations, or ineffective if the patient had serious adverse reactions, with clinical manifestations still present or even worse.

Expression levels of interleukin-2 (IL-2), tumor necrosis factor- $\alpha$ (TNF- $\alpha$ ), and high-sensitivity Creactive protein (hs-CRP) were used as indices inflammatory factors.

For MSSNS, a score below 60 indicated normal mental state, and a score within the range of 60 70 indicated mild abnormal mental state, while scores over 70 indicated abnormal mental state [10-12].

The QLI is usually based on factors such as activities of daily living, work, and interpersonal relationship, with a maximum score of 10 points. The higher the score, the better the quality of life of the patient.

\section{Statistical analysis}

Measurement data are presented as mean \pm SD and were analyzed using $t$-test. Enumeration data are expressed numbers and percentages [n
$(\%)]$, and were analyzed with $x^{2}$ test. All statistical analyses were done with SPSS 20.0 software, while graphics were drawn with GraphPad Prism 7 (GraphPad Software, San Diego, USA). Statistical significance of difference was assumed at $p<0.05$.

\section{RESULTS}

\section{Treatment effectiveness}

In study group, 28 cases were significantly effective, 19 cases were partially effective, and 3 cases were ineffective, with the overall effectiveness of $94 \%$. In control group, 17 cases were significantly effective, 18 cases partially effective, while 15 cases were ineffective, with an overall effectiveness of $70 \%$. Results showed that treatment effectiveness was significantly higher in the study group than in the control group $\left(X^{2}=9.76, P=0.002\right)$, as shown in Table 2 .

\section{Incidence of adverse reactions}

In the study group, there was 1 case of pruritus and 1 case of leucorrhea, with total incidence of $4 \%$. In the control group, there was 3 cases of pruritus, 5 cases of leucorrhea and 3 cases of nausea, with overall incidence of $22 \%$. Results showed significantly less adverse reactions in the study group than in the control group $(x 2=7.16$, $p=0.007$ ), as shown in Table 3 .

\section{Recurrence rate at 1-, 2- and 3-month post- treatment}

As shown in Table 4, values for percentage recurrence at 1,2 and 3 months after treatment were significantly lower in the study group than in control group $(p<0.05)$.

Table 2: Comparison of treatment effectiveness between the two groups $\{n,(\%)\}$

\begin{tabular}{|c|c|c|c|c|}
\hline Variable & Markedly effective & Effective & Ineffective & Overall effectiveness \\
\hline Study group $(n=50)$ & $28(56)$ & $19(38)$ & $3(6)$ & $47(94)$ \\
\hline Control group $(n=50)$ & $17(34)$ & $18(36)$ & $15(30)$ & 35 \\
\hline$x^{2}$ & & & & 9.76 \\
\hline$\hat{P}$-value & & & & 0.002 \\
\hline
\end{tabular}

Table 3: Comparison of incidence of adverse reactions between the two groups ( $\mathrm{n}, \%$ )

\begin{tabular}{lcccc}
\hline Group & Pruritus & Leucorrhea & Nausea & $\begin{array}{c}\text { Overall adverse } \\
\text { reaction rates }\end{array}$ \\
\hline Study $(\mathrm{n}=50)$ & $1(2)$ & $1(2)$ & 0 & $2(4)$ \\
Control $(\mathrm{n}=50)$ & $3(6)$ & $5(10)$ & $3(6)$ & $11(22)$ \\
$X^{2}$ & & & & 7.16 \\
$P$-value & & & & 0.007 \\
\hline
\end{tabular}


Table 4: Comparison of recurrence rate at 1, 2 and 3 months post-treatment $(n, \%)$

\begin{tabular}{lccc}
\hline Group & $\begin{array}{c}\text { 1-month post- } \\
\text { treatment }\end{array}$ & 2-months post-treatment & $\begin{array}{c}\text { 3-months post- } \\
\text { treatment }\end{array}$ \\
\hline Study $(\mathrm{n}=50)$ & $2(4)$ & $4(8)$ & $4(8)$ \\
Control $(\mathrm{n}=50)$ & $16(32)$ & $20(40)$ & $26(52)$ \\
$X^{2}$ & 5.98 & 6.06 & 9.49 \\
$P$-value & 0.01 & 0.01 & 0.002 \\
\hline
\end{tabular}

Time taken for disappearance of clinical manifestations

The clinical manifestations in patients disappeared $3.26 \pm 0.64 \mathrm{~d}$ after treatment in the study group and $4.48 \pm 1.29 \mathrm{~d}$ after treatment in the control group, much later than the control group $(\mathrm{t}=5.991, p<0.001)$.

\section{Expression levels of inflammatory factors 1 week after treatment}

The expression levels of IL-2, TNF- $\alpha$ and hsCRP in the control group were $8.81 \pm 2.30 \mathrm{pg} / \mathrm{mL}$, $47.62 \pm 7.59 \mathrm{pg} / \mathrm{L}$, and $15.54 \pm 3.51 \mathrm{mg} / \mathrm{L}$, respectively; and those of the study group were $5.99 \pm 1.42 \mathrm{pg} / \mathrm{mL}, \quad 25.08 \pm 5.73 \mathrm{pg} / \mathrm{L}$, and $10.00 \pm 3.03 \mathrm{mg} / \mathrm{L}$, respectively. There were significantly lower expression levels of IL-2, TNF$\alpha$ and hs-CRP in the study group than in control group $(p<0.05)$. These results are shown in Figure 1.
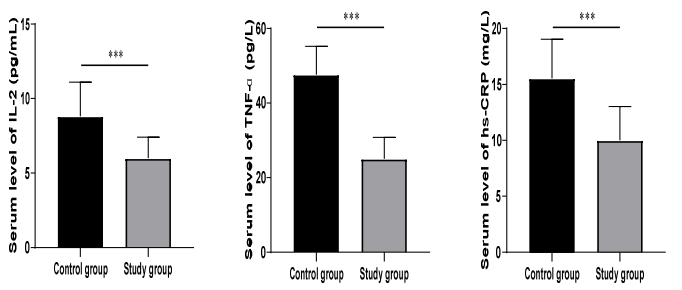

Figure 1: Comparison of expression levels of inflammatory factors 1 week after treatment. The left bar chart presents the expression levels of IL-2; the middle bar chart shows the expression levels of TNF$\alpha$; while the right chart shows the expression levels of hs-CRP. ${ }^{* *} P<0.001$

MSSNS and QLI scores 1 week after treatment

The MSSNS scores and QLI scores in the control group were $45.33 \pm 5.20$ and $63.19 \pm 7.06$; and those of the study group were $45.33 \pm 5.20$ and $72.25 \pm 9.11$.

The study group had significantly lower MSSNS score and higher QLI score than the control group $(p<0.05)$. These results are shown in Figure 2.
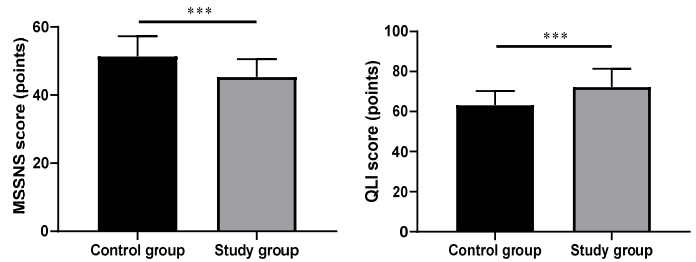

Figure 2 : Comparison of MSSNS scores and QLI scores after treatment. The left figure presented the MSSNS scores, the right figure presented the QLI scores. ${ }^{* \star *} P<0.001$

\section{DISCUSSION}

Vaginitis, a common gynecological disease during pregnancy, is caused by changes in hormonal secretion levels. Compared with nonpregnant women, pregnant women are more likely to be infected with bacteria and fungi which lead to vaginitis. Undoubtedly, vaginitis not only affects the physical health of pregnant women, it also has a certain influence on the outcome of delivery, delivery mode, and the health of the fetus $[13,14]$. In order to protect pregnant women and their fetuses, patients with vaginitis need timely treatment after diagnosis. Drugs used for treatment of vaginitis should be selected very carefully and used appropriately [15]. Nifuratel tablets and Baofukang suppository can be used in the treatment of vaginitis during pregnancy. Indeed, Nitfuratel is widely used in treating various types of infectious vaginitis with acceptable curative effect, while Baofukang suppository is used for treating vaginitis and hygropyretic leucorrhea $[16,17]$.

This study determined the efficacy and safety of combination of the two drugs in the treatment of vaginitis in pregnant women. The results showed that the effectiveness and QLI score of study group treated with combination of Baofukang and Nifuratel tablets were significantly higher than those of the control group. The criteria for defining treatment effectiveness comprised disappearance of clinical manifestations and absence of adverse reactions. It was found that combination of Baofukang suppository and Nifuratel tablet significantly enhanced therapeutic effect and improved the quality of life of patients. 
Pregnant women should maintain good living habits and mental state in pregnancy to ensure healthy development of the fetus [18]. The study investigated the quality of life of the patients so as to timely guide them. Furthermore, the study group had lower incidence of adverse reactions, lower percentage recurrence values at 1,2 and 3 months after treatment; reduced expression levels of inflammatory factors 1 week after treatment, lower MSSNS scores, as well as quicker disappearance of clinical manifestations, when compared with the control group.

After treatment, vaginitis relapses easily, especially in pregnant women. Once the relapse appears, the patient may develop drug resistance which negatively affects treatment efficacy. In this study, the levels of inflammatory factors in patients with vaginitis were increased significantly, but they were decreased after medication. Therefore, the expression levels of inflammatory factors in patients could be used to assess therapeutic effect to a certain extent, thereby guiding further treatment [19]. The treatment of vaginitis in pregnant women is associated with certain risks such as adverse reactions caused by drugs and other physical issues.

This study used the incidence of adverse reactions as an index of the safety of vaginitis treatment. The results indicated that combination of Nifuratel tablet and Baofukang suppository enhanced the disappearance of clinical manifestations, reduced recurrence and the expression levels of inflammatory factors, and significantly improved the safety of treatment. In a previous study [20], it was demonstrated a group of vaginitis patients given combined treatment with Nifuratel tablets and Baofukang suppository significantly performed better than those on monotherapy, with respect to treatment effectiveness, time taken for disappearance of clinical manifestations, and recurrence after treatment. In addition, there was no significant difference between the two monotherapy groups in overall treatment effectiveness, time taken for disappearance of clinical manifestations, and recurrence, indicating that combination of Nifuratel tablets with Baofukang suppository produced a desirable effect and high safety in the treatment of pregnant women with vaginitis. This is in agreement with results of this study.

\section{CONCLUSION}

The combination of Nifuratel tablets and Baofukang suppository significantly improves the efficacy and safety of treatment in pregnant women with vaginitis, reduces recurrence, and decreases the expression levels of inflammatory factors. Thus, this combination therapy may be useful for the management of vaginitis in pregnancy.

\section{DECLARATIONS}

\section{Conflict of interest}

No conflict of interest is associated with this work.

\section{Contribution of authors}

We declare that this work was done by the authors named in this article and all liabilities pertaining to claims relating to the content of this article will be borne by the authors.

\section{Open Access}

This is an Open Access article that uses a funding model which does not charge readers or their institutions for access and distributed under the terms of the Creative Commons Attribution License (http://creativecommons.org/licenses/by/ 4.0) and the Budapest Open Access Initiative (http://www.budapestopenaccessinitiative.org/rea d), which permit unrestricted use, distribution, and reproduction in any medium, provided the original work is properly credited.

\section{REFERENCES}

1. Durić $K$, Kovčić Hadžiabdić $S$, Durić $M$, Nikšić $H$, Uzunović A, Džudžević Čančar $H$. Efficacy and safety of three plant extracts-based formulations of vagitories in the treatment of vaginitis: a randomized controlled trial. Med Glas (Zenica) 2021; 18: 47-54.

2. Plisko O, Zodzika J, Jermakova I, Pcolkina K, Prusakevica A, Liepniece-Karele I, Donders GGG, Rezeberga D. Aerobic Vaginitis-Underestimated Risk Factor for Cervical Intraepithelial Neoplasia. Diagnostics (Basel) 2021; 11: 97.

3. Zhang $H T$, Wang $H$, Wu HS, Zeng J, Yang $Y$. Comparison of viromes in vaginal secretion from pregnant women with and without vaginitis. Virol J 2021; 18: 11.

4. Wójkowska-Mach J, Pomorska-Wesołowska M, Romanik M, Romaniszyn D. Prevalence and Antimicrobial Susceptibility Profiles of Microorganisms Associated with Lower Reproductive Tract Infections in Women from Southern Poland-Retrospective Laboratory-Based Study. Int J Environ Res Public Health 2021; 18: 335.

5. Danby CS, Althouse AD, Hillier SL, Wiesenfeld HC. Nucleic Acid Amplification Testing Compared with Cultures, Gram Stain, and Microscopy in the Diagnosis of Vaginitis. J Low Genit Tract Dis 2021; 25: 76-80.

Trop J Pharm Res, June 2021; 20(6): 1271 
6. Mension E, Alonso I, Castelo-Branco C. Genitourinary Syndrome of Menopause: Current Treatment Options in Breast Cancer Survivors - Systematic Review. Maturitas 2021; 143: 47-58.

7. Poordast T, Ghaedian L, Ghaedian L, Najib FS, Alipour $S$, Hosseinzadeh $M$, Vardanjani HM, Salehi $A$, Hosseinimehr SJ. Aloe Vera; A new treatment for atrophic vaginitis, $A$ randomized double-blinded controlled trial. J Ethnopharmacol 2021; 270: 113760.

8. Juliana NCA, Suiters MJM, Al-Nasiry S, Morré SA, Peters $R P H$, Ambrosino E. The Association Between Vaginal Microbiota Dysbiosis, Bacterial Vaginosis, and Aerobic Vaginitis, and Adverse Pregnancy Outcomes of Women Living in Sub-Saharan Africa: A Systematic Review. Front Public Health 2020; 8: 567885.

9. Department of Health, Education, and Welfare; National Commission for the Protection of Human Subjects of Biomedical and Behavioral Research. The Belmont Report. Ethical principles and guidelines for the protection of human subjects of research. J Am Coll Dent 2014; 81: 4-13.

10. Critchley HOD, Babayev E, Bulun SE, Clark S, GarciaGrau I, Gregersen PK, Kilcoyne A, Kim JJ, Lavender M, Marsh EE, et al. Menstruation: science and society. Am J Obstet Gynecol 2020; 223: 624-664.

11. Fidel PL Jr. The Neutral Vaginal $\mathrm{pH}$ in Mice That Is Typical of Most Mammalian Species Should Not Deter Research Using Experimental Murine Models of Candida Vaginitis. Infect Immun 2021; 89: e00624-20.

12. Okiki PA, Eromosele ES, Ade-Ojo $P$, Sobajo OA, Idris $O O$, Agbana RD. Occurrence of mecA and blaZ genes in methicillin-resistant Staphylococcus aureus associated with vaginitis among pregnant women in Ado-Ekiti, Nigeria. New Microbes New Infect 2020; 38: 100772.
13. Oerlemans EFM, Wuyts $S$, Bellen G, Wittouck $S$, De Boeck I, Ruban K, Allonsius CN, van den Broek MFL, Donders GGG, Lebeer S. The Dwindling Microbiota of Aerobic Vaginitis, an Inflammatory State Enriched in Pathobionts with Limited TLR Stimulation. Diagnostics (Basel) 2020; 10: 879.

14. Li Y, Xu Z, Qi H, Zhu Z, Chen S, Zhang G. Observation and Nursing of the Curative Effect of $\mathrm{Ag} / \mathrm{TiO}_{2}$ Nanomaterials on Bacterial Vaginosis and Trichomonal Vaginitis. J Nanosci Nanotechnol 2020; 20: 7419-7424.

15. Aduloju OP, Akintayo AA, Aduloju T. Prevalence of bacterial vaginosis in pregnancy in a tertiary health institution, south western Nigeria. Pan Afr Med J 2019; 33: 9.

16. Abu-Azzam O, Nasr M. In vitro anti-inflammatory potential of phloretin microemulsion as a new formulation for prospective treatment of vaginitis. Pharm Dev Technol 2020; 25: 930-935.

17. Fish ML, Grover R, Schwarz GS. Quality-of-Life Outcomes in Surgical vs Nonsurgical Treatment of Breast Cancer-Related Lymphedema: A Systematic Review. JAMA Surg 2020; 155: 513-519.

18. Sonthalia S, Aggarwal P, Das S, Sharma P, Sharma R, Singh $S$. Aerobic vaginitis - An underdiagnosed cause of vaginal discharge - Narrative review. Int J STD AIDS 2020; 31: 1018-1027.

19. Rigo GV, Tasca T. Vaginitis: Review on Drug Resistance. Curr Drug Targets 2020; 21: 1672-1686.

20. Ikegami K, Watanabe G, Kumagai J, Fujii Y, Watanabe $H$, Oite $T$. The apparition macrophage and Döderlein bacillus is negatively correlated in class I Papanicolaou smear: A morphological examination. Diagn Cytopathol 2020; 48: 1205-1210. 